\title{
Socio - economic determinants of abortion among women in Mozambique and Ghana: evidence from demographic and health
} survey

\author{
Kwamena Sekyi Dickson ${ }^{1 *}$, Kenneth Setorwu Adde ${ }^{1}$ and Bright Opoku Ahinkorah ${ }^{2}$
}

\begin{abstract}
Background: Despite the variances in abortion laws accounting for differences in incidence of abortion among African countries, it appears there is absence of literature on other factors that may also account for the differences in incidence of abortion. Specifically, there is paucity of information on how socio-demographic factors account for the disparities in prevalence of pregnancy termination among women of reproductive age in sub-Saharan Africa. In view of this, this paper examined how socio-demographic factors influence pregnancy termination among women in reproductive age in Mozambique and Ghana.

Methods: The study made use of data from the 2014 Ghana and 2011 Mozambique Demographic and Health Survey for the study. For the purpose of this study a sample of 9375 and 13,660 made up of women in their reproductive ages (15-49) in Ghana and Mozambique respectively was used. The results on the analysis of the association between socio-demographic factors and pregnancy termination are presented as odds ratio (OR) with 95\% confidence intervals (Cl).

Results: The results revealed that about 25\% of the respondents in Ghana and 9\% of the respondents in Mozambique reported ever had a pregnancy terminated. In both countries, the odds of pregnancy termination were high among women with primary education, those in the older age groups, women who were Christians and women who were employed. Similarly, higher odds of pregnancy termination were found among ever married women, those who less than four births or more and those who have had access to social media (radio and television).

Conclusion: To reduce unintended pregnancies that could lead to pregnancy termination, there is a need for regular integrated community-based outreach programs targeted at generating community responsiveness of effective contraception and prevention of unintended pregnancy.
\end{abstract}

Keywords: Social - Economic, Abortion, Mozambique, Ghana

\section{Background}

Globally, 56 million abortions occur each year, with 22 million being unsafe [1]. According to the World Health Organization (WHO) unsafe abortion as a procedure for terminating a pregnancy performed by persons lacking the necessary skills or in an environment not in conformity with minimal medical standards, or both [2].

\footnotetext{
*Correspondence: nadicx@gmail.com

${ }^{1}$ Department of Population and Health, University of Cape Coast, Cape Coast, Ghana

Full list of author information is available at the end of the article
}

Prior to the improvement of medicine, the prevalence of unsafe abortions was high and this exerted a hefty burden on women's lives. Currently, the introduction of safe and efficient technologies and skills to perform induced abortion is geared in the direction of totally eliminating unsafe abortions and related deaths and providing universal access to these services [3]. In almost all developed countries, there are legal laws that bind safe abortions upon request or under broad social and economic grounds, and abortion services are generally accessible to most women. However, access to safe abortion in some developing 
countries is limited to a restricted number of narrow conditions [4]. As at 2015, about $90 \%$ of women within the childbearing age in Africa lived in countries with restrictive abortion laws [5]. In such countries, a smaller percentage of women satisfy the legal conditions, or are aware of their rights to receive the safe abortion services to which they are legally entitled. Moreover, providers may not be aware of the legal provisions or may be averse to offer legal abortion services [6]. The legal restrictions lead many women to seek services in other countries, from unskilled providers or under unhygienic conditions, exposing them to a significant risk of death or disability [7].

In Africa, countries such as Algeria, Botswana, Gambia, Liberia, Mauritius, Namibia, Sierra Leone and Ghana permit abortion only when it is done with the intention of saving the life of a woman or to preserve her physical and mental health. On the other hand, four countries in Africa (Cape Verde, Mozambique, South Africa and Tunisia) have relatively liberal abortion laws and allow pregnancy termination devoid of restriction as to reason, but with gestational limits [5]. Due the fact that most of abortions are considered illegal and unsafe in Africa, the total prevalence of abortion in Africa was stable between 2003 and 2008, recording almost 29 abortions per 1000 women of childbearing age. The prevalence, however, differed between countries where abortion is legalised and those that have restrictions on abortion [8]. According to the World Health Organization [8], countries in Africa where abortion is legalised have been found to have the lowest abortion rate. On the other hand, countries that have restrictions on abortion usually experience high incidence of abortion. Studies that have been conducted on the practice of abortion in Ghana indicate that at least $47 \%$ of women have experienced an abortion at least once in their life [9-12]. An ethnographic research in Mozambique among traditional practitioners indicated abortion continues to be among the most common care sought after [13]. The prevalence of abortion within the Southern Africa subregion, dominated by South Africa was 15 per 1000 women in 2008 [8]. Notwithstanding its rate, abortion remains one of the most neglected global public health challenges. When abortion is considered legal, safe, and is made easily accessible, women's health improve rapidly. On the contrary, the health of women worsens when there is difficulty in getting access to safe abortion and women resort to unsafe abortions [14].

Studies have also shown that socio-demographic charateristics also affect the utilisation of health care facilities by women in dealing with maternal health issues [15-17]. Nwosu et al. [18] in their study revealed that health seeking behaviour increases with age and deceases at older age. However, Ghosh, Chakrabarti, Chakraborty, et al. [19] also shown in their study that education plays a vital role in the utilisation of health care which in turn influences maternal deaths.
Unsafe abortions account for 70,000 maternal deaths annually and are also responsible for about 5 million women who are suffering from temporary or permanent disability [4, 20]. Globally, developing countries experiece almost all abortion-related deaths, with more deaths occurring in Africa. At least 9\% of maternal deaths $(16,000)$ that occur annually in Africa are due to unsafe abortion [5]. Incomplete abortion, excessive loss of blood and infection have been found to be the most common complications that occur as a result of unsafe abortion. Rare, but very serious complications including, septic shock, damage of internal organs and swelling of the peritoneum. Unsafe abortion also has undesirable consequences beyond its immediate effects on women's health. For example, complications as a results of unsafe abortion can lead to a reduction in women's productivity, increase the economic burden on poor families, and bring about substantial costs to already struggling public health systems [21]. Despite the differences in abortion laws accounting for differences in prevalence of abortion among African countries, it appears there is inadequate literature on other factors that may also account for the differences in prevalence of abortion. Specifically, there is paucity of information on how socio-demographic factors account for the disparities in prevalence of pregnancy termination among women of reproductive age in sub-Saharan Africa. In view of this, this paper examined how socio-demographic factors influence pregnancy termination among women in reproductive age in Mozambique and Ghana.

\section{Data and methods}

\section{Data sources}

The 2014 Ghana and 2011 Mozambique Demographic and Health Survey data were used for the study. Demographic and Health Survey is a nationwide survey which is designed and conducted every five years. The DHS focuses on child and maternal health and is designed to provide adequate data to monitor the population and health situation in Ghana and Mozambique. Demographic and Health Survey was carried out by the Ghana Statistical Service and Ministerio da Saude - MISAU/ Moçambique, Instituto Nacional de Estatística - INE/ Moçambique with ICF Macro an international company, giving the technical support needed for the survey through MEASURE DHS. The survey employs a stratified two stage sampling technique. The first stage involves the selection of points or clusters (enumeration areas [EAs]). The second stage is the systematic sampling of households listed in each cluster or EA. All women in their reproductive ages (15-49) belonging to selected households or visitors who slept in the household on the night before the survey were considered for interview. The 2014 version of the Ghana Demographic 
and Health Survey (GDHS) interviewed 9396 women between the ages 15 and 49 from 12, 831 households covering 427 clusters throughout Ghana. It had a response rate of 97\% [22]. Whereas the 2011 version of Mozambique Demographic and Health Survey (MDHS) interviewed 13,745 women between the ages 15 and 49 from 13,718 households throughout Mozambique. It had a response rate of $99.8 \%$ [23]. For the purpose of this study a sample of 13,660 was used. Permission to use the data set was given us by the MEASURE DHS following the assessment of a concept note. The dataset is available to the public (www.measuredhs.com).

\section{Definition of variables}

The dependent variable employed for this study was "pregnancy termination" which was derived from the question "have you ever had a terminated pregnancy" and responses were coded $0=$ "No" and $1=$ "Yes". Eleven independent variables were used for the study, these were; residence, maternal age, marital status, educational level, wealth status, religion, birth history, and occupation. Others included frequency of watching television, frequency of reading newspapers or magazine and frequency of listening to radio, which were used to as proxy to examine the influence media.

\section{Measurement of variables}

Residence was coded as urban $=1$ rural $=2$, age was categorized into, $15-19=1,20-24=2,25-29=3,20-34=4$, $35-39=5,40-44=6,45-49=7$. Marital status was captured as never in union $=1$, married $=2$, living with partner $=3$, widowed $=4$, divorced $=5$ and separated $=6$. Educational level was classified into four categories: No education $=1$, primary $=2$, secondary $=3$ and higher $=4$. Wealth status was categorized in poorest $=1$, poorer $=2$, middle $=3$, richer $=4$ and richest $=5$. Religion was recoded as Christian $=1$, Islam $=2$ and traditional $/$ spiritual $/$ other $/$ no religion $=3$. Birth history was also captured as Zero birth $=1$, one birth $=2$, two births $=3$, three births $=4$ and four births or more $=5$. Occupation was also categorized into two thus, unemployed $=1$ and employed $=2$. Frequency of watching television was captured as "not at all" $=1$, "less than once a week" $=2$, "at least once a week" $=3$. Frequency of reading newspaper or magazine was coded as "not at all" $=1$, "less than once a week" $=2$, "at least once a week" $=3$. Frequency of listening to radio was categorized as "not at all" $=1$, "less than once a week" $=2$, "at least once a week" $=3$.

\section{Statistical analysis}

Pearson Chi - square test was conducted to examine the relationship between background characteristics and pregnancy termination. Next, univariate and multivariate binary logistic analysis were conducted to assess the association between women's socio-demographic and behaviour factors and pregnancy termination. The results from the logistic regression analysis are presented as odds ratio (OR) with 95\% confidence intervals (CI). The binary logistic regression was employed since the dependent variable was a dichotomous variable and it allows the predictions on a mixture of continuous and categorical variables. All the analysis was stratified by country. All analysis was done using the women file from both Ghana and Mozambique separated with the aim of comparison among the countries. All analysis was done using STATA version 13.

\section{Results}

\section{Background characteristics}

Table 1 presents results on respondents who have ever had a pregnancy terminated based on their background characteristics which consist of age, wealth status, level of education, religion, birth history, frequency of listening to radio, frequency of reading newspaper or magazine, frequency of watching television, marital status, residence and occupation. The results revealed that about $25 \%$ of the respondents in Ghana and 9\% of the respondents in Mozambique reported ever had a pregnancy terminated. Thirty $-4 \%$ and $11 \%$ of respondents aged 35-39 years had ever had a pregnancy terminated in Ghana and Mozambique respectively. Again, 27 and $13 \%$ of respondents with richest wealth status had ever had a pregnancy terminated in Ghana and Mozambique respectively. In Ghana, 25\% of respondents with primary level of education had ever had a pregnancy terminated but in Mozambique, 17\% of respondents with higher education had ever terminated a pregnancy (see Table 1).

It was also observed that about $26 \%$ of respondents in Ghana who are Christians had ever terminated a pregnancy but in Mozambique, 11\% of respondents belonging to the Traditional/spiritual/other/no religion had ever terminated a pregnancy. About $32 \%$ of respondents in Ghana with three births had ever terminated a pregnancy while in Mozambique, about 10\% of respondents with one birth had ever terminated a pregnancy. In Ghana, $26 \%$ of respondents who never read newspaper or magazine had ever terminated a pregnancy but in Mozambique, $13 \%$ of respondents who read newspaper or magazine less than once a week had ever terminated a pregnancy. In Ghana, 26\% of respondents who listened to radio at least once a week had ever terminated a pregnancy while in Mozambique, about $10 \%$ of respondents who listened to radio less than once a week had ever terminated a pregnancy (see Table 1).

Results of the study also showed that about 27 and $13 \%$ of respondents in Ghana and Mozambique respectively who watched television at least once a week had ever terminated a pregnancy. Again, 38 and $12 \%$ of 
Table 1 Background characteristics and prevalence of pregnancy termination in Ghana (DHS 2014) and Mozambique (DHS 2011)

\begin{tabular}{|c|c|c|c|c|c|c|}
\hline \multirow[t]{2}{*}{ Variable } & \multicolumn{3}{|l|}{ Ghana } & \multicolumn{3}{|c|}{ Mozambique } \\
\hline & $N=9375$ & Proportions & $X^{2}: P$ value & $N=13,660$ & Proportions & $X^{2}: P$ value \\
\hline Age & & & $X^{2}=588: p<0.000$ & & & $x^{2}=173: p<0.000$ \\
\hline $15-19$ & 53 & 3.3 & & 107 & 3.5 & \\
\hline $20-24$ & 304 & 18.9 & & 232 & 9.5 & \\
\hline $25-29$ & 443 & 27.2 & & 241 & 10.7 & \\
\hline $30-34$ & 462 & 33.8 & & 216 & 10.9 & \\
\hline $35-39$ & 446 & 34.6 & & 191 & 11.3 & \\
\hline $40-44$ & 322 & 31.3 & & 108 & 9.4 & \\
\hline $45-49$ & 287 & 33.5 & & 105 & 9.6 & \\
\hline Wealth status & & & $X^{2}=155: p<0.000$ & & & $X^{2}=98: p<0.000$ \\
\hline Poorest & 223 & 15.4 & & 177 & 6.8 & \\
\hline Poorer & 340 & 20.8 & & 172 & 6.8 & \\
\hline Middle & 516 & 26.7 & & 177 & 6.9 & \\
\hline Richer & 603 & 28.6 & & 259 & 9.4 & \\
\hline Richest & 626 & 28.6 & & 415 & 13.0 & \\
\hline Level of education & & & $X^{2}=6: p<0.126$ & & & $X^{2}=31: p<0.000$ \\
\hline No education & 409 & 22.9 & & 300 & 7.0 & \\
\hline Primary & 448 & 27.0 & & 619 & 9.0 & \\
\hline Secondary & 1328 & 25.0 & & 251 & 10.8 & \\
\hline Higher & 132 & 22.2 & & 32 & 17.2 & \\
\hline Religion & & & $X^{2}=25: p<0.000$ & & & $X^{2}=12: p<0.05$ \\
\hline Christian & 1931 & 25.7 & & 1121 & 8.9 & \\
\hline Islam & 275 & 19.5 & & 47 & 6.4 & \\
\hline Traditional/spiritual/other/no religion & 110 & 24.9 & & 33 & 11.4 & \\
\hline Birth history & & & $X^{2}=286: p<0.000$ & & & $x^{2}=40: p<0.000$ \\
\hline Zero birth & 401 & 13.7 & & 189 & 6.4 & \\
\hline One birth & 376 & 28.4 & & 222 & 10.2 & \\
\hline Two births & 420 & 32.0 & & 190 & 9.7 & \\
\hline Three births & 363 & 32.2 & & 437 & 8.9 & \\
\hline Four births or more & 757 & 28.2 & & & & \\
\hline Frequency of reading newspaper or magazine & & & $X^{2}=6: p<0.055$ & & & $x^{2}=32: p<0.000$ \\
\hline Not at all & 1959 & 25.8 & & 959 & 8.3 & \\
\hline Less than once a week & 208 & 21.7 & & 114 & 13.0 & \\
\hline At least once a week & 151 & 24.7 & & 128 & 10.8 & \\
\hline Frequency of listening to radio & & & $x^{2}=30: 0.000$ & & & $X^{2}=21: p<0.000$ \\
\hline Not at all & 273 & 18.6 & & 362 & 7.5 & \\
\hline Less than once a week & 768 & 25.4 & & 292 & 9.6 & \\
\hline At least once a week & 1276 & 26.1 & & 547 & 9.4 & \\
\hline Frequency of watching television & & & $X^{2}=61: 0.000$ & & & $X^{2}=98: p<0.000$ \\
\hline Not at all & 426 & 19.3 & & 631 & 7.1 & \\
\hline Less than once a week & 614 & 25.4 & & 156 & 10.4 & \\
\hline At least once a week & 1277 & 26.9 & & 414 & 12.5 & \\
\hline Marital status & & & $X^{2}=375: 0.000$ & & & $x^{2}=146: p<0.000$ \\
\hline
\end{tabular}


Table 1 Background characteristics and prevalence of pregnancy termination in Ghana (DHS 2014) and Mozambique (DHS 2011) (Continued)

\begin{tabular}{|c|c|c|c|c|c|c|}
\hline \multirow[t]{2}{*}{ Variable } & \multicolumn{3}{|l|}{ Ghana } & \multicolumn{3}{|c|}{ Mozambique } \\
\hline & $N=9375$ & Proportions & $X^{2}: P$ value & $N=13,660$ & Proportions & $X^{2}: P$ value \\
\hline Never married & 378 & 12.3 & & 107 & 4.3 & \\
\hline Married & 1181 & 29.9 & & 535 & 8.8 & \\
\hline Living with partner & 430 & 31.8 & & 355 & 11.2 & \\
\hline Widowed & 74 & 29.3 & & 45 & 8.73 & \\
\hline Divorced & 83 & 29.7 & & 29 & 9.7 & \\
\hline Separated & 171 & 38.3 & & 131 & 12.2 & \\
\hline Residence & & & $X^{2}=60: 0.000$ & & & $X^{2}=83: p<0.000$ \\
\hline Urban & 1422 & 28.2 & & 564 & 11.9 & \\
\hline Rural & 895 & 20.6 & & 637 & 7.1 & \\
\hline Occupation & & & $X^{2}=236: 0.000$ & & & $X^{2}=192: p<0.000$ \\
\hline Unemployed & 269 & 12.2 & & 415 & 5.7 & \\
\hline Employed & 2048 & 28.5 & & 786 & 12.4 & \\
\hline \multicolumn{7}{|l|}{ Terminated pregnancy } \\
\hline No & 7057 & 74.3 & & 12,459 & 91.2 & \\
\hline Yes & 2317 & 24.7 & & 1201 & 8.8 & \\
\hline
\end{tabular}

Source: Computed from Ghana DHS 2014, Mozambique DHS2011

respondents who were separated had ever terminated a pregnancy in Ghana and Mozambique respectively. By residence, 28 and $12 \%$ of respondents in Ghana and Mozambique respectively had ever terminated a pregnancy. About 29 and $12 \%$ of respondents who were employed in Ghana and Mozambique respectively had ever terminated a pregnancy (see Table 1$)$.

\section{Binary logistic regression}

The binary logistic regression analysis carried out between background characteristics and pregnancy termination can be seen in Table 2. In Ghana, the results showed significant associations between ever terminated a pregnancy and wealth status (poorest), level of education (primary and higher), age, religion, occupation, marital status (married, living together, separated), residence, birth history, frequency of reading newspaper or magazine (at least once a week), frequency of listening to radio, and frequency of watching television (at least once a week). In Mozambique, the results showed significant associations between ever terminated a pregnancy and wealth status (poorest, poorer and middle), level of education (primary and secondary), age, religion (Christian), occupation, marital status, residence, birth history and frequency of watching television (at least once a week).

The prevalence of ever had a pregnancy terminated was low among women with the poorest wealth status compared to women with richest wealth status in both Ghana and Mozambique, although the association is weaker in Ghana. The OR in Ghana is 0.70 (95\% Cl: (0.48-1.01) compared to 0.72 (95\% CI: (0.51-1.03) in Mozambique. Women with primary education in both countries were more likely to have ever terminated a pregnancy compared to those with no education, although the association was stronger in Ghana. The OR in Ghana is 1.35 (95\% Cl: $(1.10-1.67)$ compared to OR of 1.21 (95\% CI: (1.01-1.46) in Mozambique. In Ghana, the likelihood of pregnancy termination was low among women with higher educational level compared to those with no education $(\mathrm{OR}=0.74,95 \% \mathrm{CI}=0.53-1.04)$ With age, the prevalence of ever terminated a pregnancy was higher among women 45-49 years compared women 15-19 years, although the association was stronger in Ghana. The OR in Ghana is 14.23 (95\% Cl: (8.94-22.66) compared to OR of 3.22 (95\% CI: (2.11-4.89) in Mozambique. In both countries, ever had a pregnancy terminated was high among Christians compared to Muslims, although the association is stronger in Mozambique. The OR Ghana is 1.23 (95\% CI: (1.991.52) in Ghana compared to OR of 1.42 (95\% Cl: (0.962.10) in Mozambique.

With occupation, the prevalence of ever had a pregnancy terminated was high among employed women in both Ghana and Mozambique compared to unemployed women, although the association is stronger in Mozambique. The OR in Ghana is 1.38 (95\% Cl: (1.131.68) compared to OR of 2.05 (95\% CI: (1.77-2.38) in Mozambique. Women who were separated were more likely to have had a pregnancy terminated compared to 
Table 2 Binary logistic regression on pregnancy termination among women in Ghana (DHS 2014) and Mozambique (DHS 2011)

\begin{tabular}{|c|c|c|}
\hline \multirow[t]{2}{*}{ Independent Variables } & Ghana & Mozambique \\
\hline & OR (95\% Cl) & OR $(95 \% \mathrm{Cl})$ \\
\hline \multicolumn{3}{|l|}{ Wealth status } \\
\hline Poorest & $0.70^{*}(0.48-1.01)$ & $0.72^{*}(0.51-1.03)$ \\
\hline Poorer & $0.89(0.64-1.23)$ & $0.72 *(0.52-1.00)$ \\
\hline Middle & $1.05(0.83-1.34)$ & $0.73^{*}(0.52-1.00)$ \\
\hline Richer & $1.04(0.85-1.26)$ & $0.92(0.73-1.16)$ \\
\hline Richest & Ref & Ref \\
\hline \multicolumn{3}{|l|}{ Level of education } \\
\hline No education & Ref & Ref \\
\hline Primary & $1.35^{* *}(1.10-1.67)$ & $1.21 * *(1.01-1.46)$ \\
\hline Secondary & $1.13(0.93-1.39)$ & $1.34^{* *}(1.02-1.76)$ \\
\hline Higher & $0.74^{*}(0.53-1.04)$ & 1.14(0.70-1.16) \\
\hline \multicolumn{3}{|l|}{ Age } \\
\hline $15-19$ & Ref & Ref \\
\hline $20-24$ & $5.61^{* * *}(3.75-8.41)$ & $2.48^{* * *}(1.75-3.50)$ \\
\hline $25-29$ & $8.79 * * *(5.78-13.36)$ & $3.06^{* * *}(2.13-4.40)$ \\
\hline $30-34$ & $12.13^{* * *}(7.81-18.88)$ & $3.37^{* * *}(2.28-4.97)$ \\
\hline $35-39$ & $13.62^{* * *}(8.85-20.96)$ & $3.67^{* * *}(2.45-5.51)$ \\
\hline $40-44$ & $11.99^{* * *}(7.54-19.06)$ & $2.98^{* * *}(1.95-4.57)$ \\
\hline $45-49$ & $14.23^{* * *}(8.94-22.66)$ & $3.22^{* * *}(2.11-4.89)$ \\
\hline \multicolumn{3}{|l|}{ Religion } \\
\hline Christian & $1.23^{*}(0.99-1.52)$ & $1.42 *(0.96-2.10)$ \\
\hline Islam & Ref & Ref \\
\hline Traditional/spiritual/other/no religion & $1.42^{* *}(1.03-1.97)$ & $1.50(0.88-2.56)$ \\
\hline \multicolumn{3}{|l|}{ Occupation } \\
\hline Unemployed & Ref & Ref \\
\hline Employed & $1.38^{* *}(1.13-1.68)$ & $2.05^{* * *}(1.77-2.38)$ \\
\hline \multicolumn{3}{|l|}{ Marital status } \\
\hline Never married & Ref & Ref \\
\hline Married & $1.47^{* *}(1.09-2.00)$ & $2.22^{* * *}(1.58-3.12)$ \\
\hline Living together & $1.67^{* *}(1.24-2.24)$ & $2.32^{* * *}(1.64-3.28)$ \\
\hline Widowed & $1.23(0.80-1.88)$ & $1.76^{* *}(1.10-2.83)$ \\
\hline Divorced & $1.11(0.69-1.78)$ & $1.97^{* *}(1.09-3.54)$ \\
\hline Separated & $1.74^{* *}(1.18-2.56)$ & $2.38^{* * *}(1.61-3.50)$ \\
\hline \multicolumn{3}{|l|}{ Residence } \\
\hline Urban & Ref & Ref \\
\hline Rural & $0.81^{*}(0.65-1.02)$ & $0.78^{* *}(0.61-1.00)$ \\
\hline \multicolumn{3}{|l|}{ Birth history } \\
\hline Zero birth & $1.71^{* *}(1.19-2.46)$ & $2.38^{* * *}(1.61-3.50)$ \\
\hline One birth & $1.69^{* * *}(1.32-2.15)$ & $1.64^{* * *}(1.64-3.28)$ \\
\hline Two births & $1.43^{* *}(1.15-1.78)$ & $1.76 * *(1.10-2.83)$ \\
\hline Three births & $1.23^{*}(1.00-1.52)$ & $2.05^{* * *}(1.51-2.72)$ \\
\hline Four births or more & Ref & Ref \\
\hline
\end{tabular}


Table 2 Binary logistic regression on pregnancy termination among women in Ghana (DHS 2014) and Mozambique (DHS 2011) (Continued)

\begin{tabular}{|c|c|c|}
\hline \multirow[t]{2}{*}{ Independent Variables } & Ghana & Mozambique \\
\hline & OR $(95 \% \mathrm{Cl})$ & OR $(95 \% \mathrm{Cl})$ \\
\hline Not at all & Ref & Ref \\
\hline Less than once a week & $0.91(0.71-1.16)$ & $1.08(0.83-1.42)$ \\
\hline At least once a week & $0.68^{* *}(0.50-0.92)$ & $0.89(0.68-1.17)$ \\
\hline \multicolumn{3}{|c|}{ Frequency of listening to radio } \\
\hline Not at all & Ref & Ref \\
\hline Less than once a week & $1.27^{* *}(1.04-1.55)$ & $1.16(0.94-1.44)$ \\
\hline At least once a week & $1.22^{*}(1.01-1.48)$ & $1.14(0.93-1.39)$ \\
\hline \multicolumn{3}{|c|}{ Frequency of watching television } \\
\hline Not at all & Ref & Ref \\
\hline Less than once a week & $1.16(0.96-1.41)$ & $1.07(0.83-1.38)$ \\
\hline At least once a week & $1.23^{* *}(1.04-1.46)$ & $1.24^{*}(0.98-1.57)$ \\
\hline
\end{tabular}

${ }^{*} p<1.0{ }^{* *} p<0.05{ }^{* * *} p<0.001$ OR $=$ Odds Ratio Ref $=$ reference category

Computed from Ghana DHS 2014, Mozambique DHS2011

women who were never married in both Ghana and Mozambique, although the association was stronger in Mozambique. The OR in Ghana is 1.74 (95\% Cl: (1.182.56) compared to 2.38 (95\% CI: (1.61-3.50) in Mozambique. Women in rural areas were significantly less likely to have ever terminated a pregnancy in both Ghana and Mozambique compared to women in urban areas, although the odds were smaller in Mozambique. The OR in Ghana is 0.81 (95\% Cl: $(0.65-1.02)$ compared to 0.78 (95\% CI: (0.61-1.00) in Mozambique.

The prevalence of ever had a pregnancy terminated was also high among women with zero birth history in both Ghana and Mozambique, although the association was stronger in Mozambique. The OR in Ghana is 1.71 (95\% Cl: (1.19-2.46) compared to 2.38 (95\% CI: (1.613.50) in Mozambique. Women who read newspaper or magazine in Ghana were less likely to have ever terminated a pregnancy compared to those who never read newspaper or magazine $(\mathrm{OR}=0.68, \mathrm{CI}=0.51-0.92)$. Again, women who listened to radio less than once a week in Ghana were more likely to have ever terminated a pregnancy compared to those who never listened to radio. The prevalence of ever had a pregnancy terminated was high among women who watch television at least once a week compared to those who never watch television, although the association was higher in Mozambique. The OR in Ghana is 1.23 (95\% Cl: (1.041.46) compared to $1.24 \quad(95 \%$ CI: $(0.98-1.57)$ in Mozambique.

\section{Discussion}

The current study observed that the prevalence of ever terminating a pregnancy among women in their reproductive age was high in Ghana (25\%) and low in
Mozambique (9\%). This is consistent with the findings obtained by the World Health Organization [8], where abortion was high among countries that had restrictions on abortion and low in countries where abortion is legalised. In both countries, the study showed a reduction in the odds of terminating a pregnancy among women within the poorest wealth status, women who were unemployed and those from the rural areas. This is consistent with previous studies in China [24], Napal [25] and Ghana [26, 27], where wealth status, employment and residence were found to be associated with prevalence of abortion. The low prevalence of pregnancy termination among women from the rural areas, who are unemployed and with poorest wealth status can be explained by the fact that wealthiest women who mostly live in urban areas and are usually employed are financially empowered and can afford to terminate a pregnancy as compared to poor women [28, 29]. Perhaps these findings explain the increased likelihood of the wealthiest women to have induced abortion. Another possible explanation for the lower odds of pregnancy termination among women in rural areas could be low access to abortion services due to disparities in distribution of health resources among rural and urban areas [30-32].

Our study also found a statistically significant difference in pregnancy termination with level of education in both Ghana and Mozambique. Specifically, women with primary level of education were more likely to have had a pregnancy terminated. Women with higher level of education were also likely to have ever had a pregnancy terminated in Ghana. The relationship between pregnancy termination and level of education is consistent with the findings of previous studies in Ethiopia in which 
women with higher education were not likely to have induced abortion [33] Studies have also shown that education and employment play a key role in determining whether a woman will keep a pregnancy or terminate it. The observation that women with higher education were less likely to have terminated a pregnancy is consistent with studies that have established a linear relationship between contraceptive use and education [34-36]. Thus, women with higher education are more likely to use contraceptives to avoid unintended pregnancies that are likely to result in abortion. On the contrary, studies in China [24] and Ghana [26, 37] found that more educated women have a higher likelihood of induced abortion.

The likelihood of terminating a pregnancy varied by age with the odds of pregnancy termination high among women 45-49 years. Consistent findings were obtained in previous studies in Ethiopia [33], Ghana [37] and South Africa [38], where abortion was found to be high among older women. On the contrary, other studies in Ghana, Kenya, Nigeria, and Ethiopia [39-42] have found that the prevalence of abortion is high among younger women compared to older ones. In many settings, it is alleged that distribution by age of abortion is high among women in the youngest age groups who want to postpone childbearing and women at the end of their childbearing years, who believe they cannot get pregnant at that age, are most likely to get induced abortions. One elucidation may be the perceived need or lack thereof, for contraception at the end of childbearing years, or lack of awareness or unmet need for contraception at the youngest age groups [37].

It was also observed that Islamic women were less likely to terminate a pregnancy as compared to Christians, traditionalist and women who belonged to other religions. This corroborates the findings of Klutsey [26] and Ahiadeke [39], where prevalence of abortion was found to be high among Christians. The low prevalence of abortion among Muslim women could be attributed to the strict rules and punishments guiding the Islamic religion. Our study also found that women pregnancy termination was low among unmarried women compared to women with other marital status. Consistent with the findings of our study, a study in Nigeria also found high prevalence of abortion among married women compared to never married women [43, 44]. A previous study in South Africa [37] also found that single women were significantly less likely to have a spontaneous abortion or a still birth than to have a live birth. The findings of a study in Nepal [45] explained that the prevalence of abortion was high among unmarried women because never-married women expected to experience more undesirable responses from health care workers, family and friends if they were to have an abortion than were married-women.
With regards to birth history, our study observed that women with no children were more likely to terminate a pregnancy as compared to women with parity 4 and above. One of the possible explanations could be that women with no children are likely to be adolescents, belonging the younger age category. If this is so, then the tendency abortion could be high among women of this age category since the rate of unintended pregnancies that often result in abortion has been found to be high among younger women due to unmet need for family planning [36]. Women who had access to social media (radio and television) were found to be more likely to have had a pregnancy terminated compared to those who had no access to media. The importance of media in providing information about how and where to terminate a pregnancy could account for the association between media exposure and the prevalence of pregnancy termination. Women who have access to social media may also be aware of the abortion laws in their country and are less likely to be stigmatised by society in their quest to have a pregnancy terminated.

\section{Conclusion}

Although similar demographic variables provided an understanding of pregnancy termination among women in reproductive age in Ghana and Mozambique, there were variations in relation to how each demographic variable influenced pregnancy termination. In both countries, the odds of pregnancy termination were high among women with primary education, those in the older age groups, women who were Christians and women who were employed. Similarly, higher odds of pregnancy termination were found among ever married women, those who less than four births or more and those who have had access to social media (radio and television). On the contrary, pregnancy termination was low among women within the poorest wealth status, women from rural areas and women who read newspaper or magazine at least once a week. To reduce unintended pregnancies that could lead to pregnancy termination, there is a need for regular integrated community-based outreach programs targeted at generating community awareness of effective contraception and prevention of unintended pregnancy. Pragmatic steps should be taken to make health systems easily accessible to women seeking abortion services.

\section{Acknowledgements}

We acknowledge Measure DHS for providing us with the data upon which the findings of this study were based.

\section{Funding}

The design of questionnaires and data collection was funded by measure DHS and the government of Ghana and the government of Lesotho through the ministry of health. This research, the analysis, and interpretation 
of data and in writing the manuscript received no specific grant from any funding agency in the public, commercial or non - for - profit sectors.

\section{Availability of data and materials}

The dataset is available to the public freely at www.measuredhs.com. Questionnaires used for the survey are attached to the final report published, which can be found at: http://dhsprogram.com/publications/publicationFR307-DHS-Final-Reports.cfm

http://dhsprogram.com/publications/publication-FR266-DHS-FinalReports.cfm

\section{Authors' contributions}

KSD conceived the study, designed and performed the analysis and the write up on methods. KSA and BOA designed first draft of the manuscript. $\mathrm{KSD}, \mathrm{KSA}$ and $\mathrm{BOA}$ revised the manuscript for intellectual content and gave consent for the version to be published. All authors have read and approved final manuscript.

\section{Competing interest}

The authors declare that they have no competing interests.

\section{Ethics approval and consent to participate}

All procedures performed in studies involving human participants were in accordance with the ethical standards of the institutional and/or national research committee and with the 1964 Helsinki declaration and its later amendments or comparable ethical standards.

Consent to participate is not applicable to our study since it utilised DHS data.

\section{Consent for publication}

Not applicable.

\section{Publisher's Note}

Springer Nature remains neutral with regard to jurisdictional claims in published maps and institutional affiliations.

\section{Author details}

${ }^{1}$ Department of Population and Health, University of Cape Coast, Cape Coast, Ghana. ${ }^{2}$ Department of Health, Physical Education and Recreation, University of Cape Coast, Cape Coast, Ghana.

\section{Received: 24 July 2017 Accepted: 15 June 2018}

Published online: 19 July 2018

\section{References}

1. World Health Organisation, "Fact sheet: Preventing unsafe abortion". Geneva: Author. Retrieved from http://www.who.int/mediacentre/ factsheets/fs388/en/ On 30/08/2016.2016.

2. Maternal Health and Safe Motherhood Programme. The prevention and management of unsafe abortion: report of a technical working group (WHO/MSM/92.5). Geneva: World Health Organization; 1993. p. 2.

3. World Health Organization. Unsafe abortion: global and regional estimates of incidence of unsafe abortion and associated mortality in 2008. Geneva: World Health Organization; 2011

4. United Nations. World abortion policies. New York: United Nations; 2011

5. G. Sedgh, J. Bearak, S. Singh, A. Bankole, A. Popinchalk, B. Ganatra, , ... and H. B. Johnston, "Abortion incidence between 1990 and 2014: global, regional, and subregional levels and trends". Lancet, 388(10041), 258-267.2016.

6. Schuster S. Women's experiences of the abortion law in Cameroon: "what really matters". Reprod Health Matters. 2010;18(35):137-44.

7. World Health Organization. Safe abortion: technical and policy guidance for health systems. Geneva: WHO; 2012

8. World Health Organization, "Facts on induced abortion worldwide". World Health Organization, Geneva. http://www.who. int/reproductivehealth/ publications/unsafe_abortion/induced_abortion_2012.pdf. 2012

9. Morhe ES, Tagbor HK, Ankobea FK, Danso KA. Reproductive experiences of teenagers in the Ejisu-Juabeng district of Ghana. Int J Gynaecol Obstet. 2012:118(2):137-40.

10. Sundaram A, Juarez F, Bankole A, Singh S. Factors associated with abortion-seeking and obtaining a safe abortion in Ghana. Stud Fam Plan. 2012:273-86.
11. Ghana Statistical Service (GSS), Ghana Health Service (GHS), \& ICF International. Ghana maternal health survey 2007. Calverton: GSS, GHS, and macro international; 2009.

12. Agyei WK, Biritwum RB, Ashitey AG, Hill RB. Sexual behaviour and contraception among unmarried adolescents and young adults in Greater Accra and eastern regions of Ghana. J Biosoc Sci. 2000;32(4):495-512.

13. Chapman RR. Endangering safe motherhood in Mozambique: prenatal care as pregnancy risk. Soc Sci Med. 2003;57(2):355-74.

14. Grimes DA, Benson J, Singh S, Romero M, Ganatra B, Okonofua FE, Shah $1 \mathrm{H}$. Unsafe abortion: the preventable pandemic. Lancet. 2006; 368(9550):1908-19.

15. Celik Y, Hotchkiss DR. The socioeconomic determinants of maternal health care utilisation in Turkey. Soc Sci Med. 2000;50(12):1797-806.

16. Mekonnen $\mathrm{Y}$, Mekonnen A. Factors influencing the use of maternal healthcare services in Ethiopia. J Health, Popul Nutr. 2003:21(4):374-82.

17. Woldemicael G, Tenkorang EY. Women's autonomy and maternal healthseeking behavior in Ethiopia. Mater Child Health J. 2009;14(6):988-98.

18. Nwosu, OE, Urama, E.N, and Uruakpa, C. 2012. Determinants of antenatal care services utilisation in Nigeria. Developing Country Studies, 2, No.6. www.iiste.org

19. Ghosh N, Chakrabarti I, Chakraborty M, et al. Factors affecting the healthcare-seeking behavior of mothers regarding their children in a rural community of Darjeeling district, West Bengal. Int J Med Public Heal. 2013; 3(1):12-6.

20. Iqbal S, Elisabeth A. Unsafe abortion: global and regional incidence, trends, consequences, and challenges. J Obstet Gynecol Can. 2009;31(12):1149-59.

21. Guttmacher Institute, "Abortion in Africa: 2016 Fact sheet". Retrieved May 10, 2017, from Guttmacher institute website: https://www. guttmacher.org. 2016

22. Ghana Statistical Service, Ghana Health Service, ICF Macro. Ghana Demographic and Health Survey 2014. Rockville: GSS, GHS, and ICF Macro; 2015.

23. Ministerio da Saude - MISAU/Moçambique. Instituto Nacional de Estatística INE/Moçambique and ICF International, Mozambique Demographic and Health Survey. Calverton: MISA/Moçambique, INE/Moçambique and ICF International; 2011.

24. G.P. Gao, R.J. Zhang, X.J. Zhang, X.M. Jia, X.D. Li, X. Li, ... and Y.H. Sun, "Prevalence and associated factors of induced abortion among rural married women: a cross-sectional survey in Anhui", China J Obstet and Gynaecol Res, 41(3), 383-391.2015.

25. A. Yogi, "Prevalence and factors associated with abortion in Nepal: a national cross-sectional study". (Master's Thesis, University of Tampere). 2016.

26. Klutsey E, Ankomah A. "Factors associated with induced abortion at selected hospitals in the Volta region", Ghana. Int J Women's Health. 2014;6: 809-16.

27. Adjei G, Enuameh Y, Asante KP, Baiden F, Nettey OEA, Abubakari S, et al. Predictors of abortions in rural Ghana: a cross-sectional study. BMC Public Health. 2015:15(1):202

28. Ouédraogo R, Sundby J. Social determinants and access to induced abortion in Burkina Faso: from two case studies. Obstet Gynecol Int 2014:1-6

29. Rossier C, Guiella G, Ouédraogo A, Thiéba B. Estimating clandestine abortion with the confidants' method-results from Ouagadougou, Burkina Faso. Soc Sci Med. 2006:62(1):254-66.

30. O'Donnell O. Access to health care in developing countries: breaking down demand side barriers. Cadernos de Saúde Pública. 2007:23(12):2820-34.

31. Mariolis A, Mihas C, Alevizos A, Mariolis-Sapsakos T, Marayiannis K, Papathanasiou $\mathrm{M}$, et al. Comparison of primary health care services between urban and rural settings after the introduction of the first urban health Centre in Vyronas, Greece. BMC Health Serv Res. 2008;8(1):124.

32. Alhassan RK, Nketiah-Amponsah E. Frontline staff motivation levels and health care quality in rural and urban primary health facilities: a baseline study in the Greater Accra and western regions of Ghana. Heal Econ Rev. 2016:6(1):39.

33. Tesfaye G, Hambisa MT, Semahegn A. Induced abortion and associated factors in health facilities of Guraghe zone, southern Ethiopia. J Pregnancy. 2014:1-8

34. Radulović O, Šagrić C, Višnjić A, Tasić A, Marković R. The influence of education level on family planning. Med Biol. 2006;13(1):58-64.

35. Gordon C, Sabates R, Bond R, Wubshet T. Women's education and modern contraceptive use in Ethiopia. Int J Educ. 2011;3(1):1. 
36. Jiang L, Hardee K. Women's education, family planning, or both? Application of multistate demographic projections in India. Int J Popul Res. 2014:1-9.

37. Mote $C$, Larsen-Reindorf $R$, Otupiri E, Hindin M. Factors associated with induced abortion among women in Hohoe, Ghana. Afr J Reprod Health. 2010;14:110-6.

38. Rambau NP. Levels and determinants of voluntary abortion in South Africa. Johannesburg: Doctoral dissertation, University of the Witwatersrand; 2016

39. Ahiadeke C. Incidence of induced abortion in southern Ghana. Int Fam Pan Perspective. 2001;27:96-101.

40. Guttmacher Institute, "Unsafe abortion in Kenya, in brief". Available at www. guttmacher.org 2009. Accessed on 10/05/17 2009.

41. A. Bankole, B. Oye-Adeniran, S. Singh, I. Adewole, D. Wulf, G. Sedgh and R. Hussain, "Unwanted pregnancy and induced abortion in Nigeria: causes and consequences". Available at www.guttmacher.org 2006. Accessed on 10/05/17 2006.

42. Gebreselassie H, Fetters T, Singh S, Abdella A, Gebrehiwot AY, Tesfaye S, Geressu T, Kumbi S. Caring for women with abortion complications in Ethiopia: national estimates and future implications. Int Perspect Sex Reprod Health. 2010;36(1):6-15.

43. Ibrahim IA, Onwudiegwu U. Sociodemographic determinants of complicated unsafe abortions in a semi-urban Nigerian town: a four-year review. West Indian Med J. 2012;61(2):163-7.

44. Oye-Adeniran BA, Adewole IF, Umoh AV, Fapohunda OR, Iwere N. Characteristics of abortion care seekers in south-western Nigeria. Afr J Reprod Health. 2004:81-91.

45. Puri M, Lamichhane P, Harken T, Blum M, Harper CC, Darney PD, Henderson JT. "Sometimes they used to whisper in our ears": health care workers' perceptions of the effects of abortion legalization in Nepal. BMC Public Health. 2012;12(1):297.

Ready to submit your research? Choose BMC and benefit from:

- fast, convenient online submission

- thorough peer review by experienced researchers in your field

- rapid publication on acceptance

- support for research data, including large and complex data types

- gold Open Access which fosters wider collaboration and increased citations

- maximum visibility for your research: over $100 \mathrm{M}$ website views per year 